\title{
Hong Kong Institute of Allergy and Hong Kong Society for Paediatric Immunology Allergy \& Infectious Diseases joint consensus statement 2018 on vaccination in egg-allergic patients
}

\author{
Gilbert T Chua, Philip H Li, Marco HK Ho, Ellen Lai, Vivian Ngai, Felix YS Yau, Mike YW Kwan, \\ TF Leung, TH Lee *
}

\begin{abstract}
A B S T R A C T
Vaccination of egg-allergic individuals has been a historical concern, particularly for influenza and measles-mumps-rubella-varicella vaccines that are developed in chicken egg embryos or chicken cell fibroblasts. The egg proteins in these vaccines were believed to trigger an immediate allergic reaction in egg-allergic individuals. However, recently published international guidelines have updated their recommendations and now state that these vaccines can be safely administered to egg-allergic individuals. This joint consensus statement by the Hong Kong Institute of Allergy and the Hong Kong Society for Paediatric Immunology Allergy \& Infectious Diseases summarises the updates and provides recommendations for local general practitioners and paediatricians.
\end{abstract}

Hong Kong Med J 2018;24:527-31

DOI: $10.12809 /$ hkmj177137

' GT Chua, MB, BS, MRCPCH

${ }^{2}$ PH Li, MRes (Med), MRCP

${ }^{1} \mathrm{MHK}$ Ho, MD, FRCPCH

${ }^{3} \mathrm{E}$ Lai, BPharm, MClinPharm

${ }^{3}$ V Ngai, BPharm, MClinPharm

${ }^{4}$ FYS Yau, MRCP, FHKAM (Paediatrics)

${ }^{5}$ MYW Kwan, FHKAM (Paediatrics), FHKCPaed

${ }^{6}$ TF Leung, MD, FRCPCH

${ }^{7}$ TH Lee *, SCD, FRCP

Department of Paediatrics and Adolescent Medicine, Queen Mary Hospital, Pokfulam, Hong Kong

Division of Rheumatology and Clinical Immunology, Department of Medicine, Queen Mary Hospital, Pokfulam, Hong Kong

${ }_{3}^{3}$ Department of Pharmacy, Queen Mary Hospital, Pokfulam, Hong Kong

${ }^{4}$ Department of Paediatrics and Adolescent Medicine, Queen Elizabeth Hospital, Jordan, Hong Kong

${ }^{5}$ Department of Paediatrics and Adolescent Medicine, Princess Margaret Hospital, Laichikok, Hong Kong

${ }^{6}$ Department of Paediatrics, The Chinese University of Hong Kong, Prince of Wales Hospital, Shatin, Hong Kong

${ }^{7}$ Allergy Centre, Hong Kong Sanatorium and Hospital, Happy Valley, Hong Kong

* Corresponding author: takhong.lee@hksh.com

\section{Background}

Vaccination is an important and effective method to develop active immunity against certain pathogens. It helps to prevent or reduce the risks of developing certain infectious diseases as well as moderating disease severity. However, the administration of certain vaccines, including influenza, measlesmumps-rubella (MMR), measles-mumps-rubellavaricella (MMR-V) and yellow fever vaccines, has historically been relatively, if not absolutely, contraindicated in egg-allergic individuals. This is because these vaccines are developed in chicken egg embryos or chicken cell fibroblasts, raising the concern that egg proteins (notably ovalbumin) in these vaccines may trigger an immediate allergic reaction in eggallergic individuals. As a result, previous vaccination guidelines and vaccine product information have recommended avoidance of influenza and MMR or MMR-V vaccines in individuals with a history of anaphylactic reaction to egg exposure.
Local epidemiological studies have shown that $0.4 \%-0.7 \%$ of Hong Kong children were reported by their parents to have had an adverse reaction to intake of a hen's egg. ${ }^{1,2}$ No local data for the adult population are available. However, it is important to differentiate between adverse reactions and genuine egg allergy, especially when deciding the need for vaccine avoidance. A recent United Kingdom multicentre study found that more than a third of patients with suspected egg allergy who were referred to a tertiary allergy centre for vaccination were not actually egg allergic, and all were vaccinated successfully. ${ }^{3}$

Despite the paucity of evidence, there remains some concern that administration of vaccines that could contain egg proteins, notably ovalbumin, might cause allergic reactions in egg-allergic subjects. The Centre for Health Protection recommends that mildly egg-allergic individuals can safely receive inactivated influenza vaccine in a primary care setting. However, 
香港過敏醫學會和香港兒童免疫過敏及傳染病學 會有關雞蛋敏感症患者接種疫苗之聯合聲明

\section{蔡宇程、李曦、何學工、賴愛倫、倪卓欣、游日新、關日華、} 梁廷勳、李德康

雞蛋過敏症患者接種疫苗一直令不少醫患困擾, 因為部份疫苗在生產 過程中運用雞蛋胚胎或雞隻細胞, 而其中流感疫苗及麻疹腮腺炎德國 痳疹水痘混合疫苗特別令人關注。不少人擔心疫苗內蘊含的雞蛋蛋白 可能令雞蛋過敏症患者產生即時嚴重過敏反應。不過, 近年國際醫學 界更新了建議, 並指出對雞蛋過敏的患者都可安全接種上述兩種疫 苗。有見及此, 香港過敏醫學會和香港兒童免疫過敏及傳染病學會總 結多個國際指引，以期為本地醫生提供建議。 those with confirmed or suspected egg allergy who have experienced severe reactions should be seen by an allergist/immunologist for evaluation of their egg allergy prior to administration of inactivated influenza vaccine. ${ }^{4}$

Recently published international guidelines have updated their recommendations regarding the administration of vaccines to egg-allergic individuals. This joint consensus statement by the Hong Kong Institute of Allergy and the Hong Kong Society for Paediatric Immunology Allergy \& Infectious Diseases summarises recent updates and provides recommendations for local general practitioners and paediatricians. For practical reasons, this guideline will only cover influenza and MMR/MMR-V vaccines.

Yellow fever vaccine is less commonly administered and is commonly propagated in hens' eggs. Specialist evaluation is recommended prior to vaccination for evaluation of suspected egg allergies with vaccine skin testing or consideration for desensitisation. ${ }^{3}$ An egg-free yellow fever formulation is available as an alternative.

The $\mathrm{Q}$ fever vaccine is not available in Hong Kong and therefore is not covered in this guideline.

\section{Influenza vaccine}

Influenza vaccination is well known to be effective in preventing infections caused by influenza viruses and in reducing the risk of developing complications. We reviewed the product information recommendations of Vaxigrip (Sanofi Pasteur SA, Lyon, France), Fluarix Tetra (GlaxoSmithKline Biologicals, Dresden, Germany), and FluQuadri (Sanofi Pasteur SA, Lyon, France). All recommended that patients with egg or chicken protein hypersensitivity are contra-indicated to receive their vaccines. However, upon direct communication with the respective pharmaceutical companies, all of them were reported to contain $<0.1$ $\mathrm{ug} / \mathrm{mL}$ of ovalbumin in their vaccines. Therefore, we disagree with their recommendations.

Moneret-Vautrin et $\mathrm{al}^{5}$ reported that only $1 \%$ of egg-allergic patients would develop allergic reactions at a threshold as low as $1 \mathrm{mg}$. As the quantity of ovalbumin in influenza vaccines is $\leq 1 \mu \mathrm{g} / \mathrm{dose}$, such a level of egg protein in influenza vaccines is very unlikely to trigger an allergic response in this group of patients. Thus, despite the product information recommendations and the trace amounts of ovalbumin present in these influenza vaccines, they should be safe for egg-allergic individuals, including those with a history of anaphylaxis to egg proteins.

Our view is supported by numerous international guidelines on administration of influenza vaccines to egg-allergic individuals, summarised in the Table. ${ }^{6-12}$

\section{Measles-mumps-rubella and measles-mumps-rubella-varicella vaccines}

The MMR and MMR-V vaccines are safe and effective in preventing mumps, measles, rubella, and varicella. The vaccination schedule in Hong Kong recommends that the first dose be administered at age 1 year and the second dose at Primary 1 (age 5-6 years).$^{13}$ We reviewed the product information recommendations of two MMR- $\mathrm{V}$ vaccines available in Hong Kong: Priorix-Tetra (GlaxoSmithKline plc [GSK], Brentford, UK) and ProQuad (Merck \& Co, Inc, Kenilworth [NJ], US). The manufacturers of both of these products recommend that patients with severe allergic reactions after egg ingestion should take extra precaution when receiving the vaccines. However, in direct communication with the manufacturers, GSK replied that Priorix-Tetra may contain traces of egg protein but the amount is not measured in the final product. In contrast, Merck replied that internal analysis was done for ProQuad for its egg protein content; however, they refused to disclose the information as they consider it proprietary. We disagree with their recommendations. The Table summarises international recommendations for administration of MMR/MMR-V vaccines to egg-allergic individuals. ${ }^{6,11,14-16}$ It is recommended that all patients, including those with suspected or confirmed egg allergy, should receive the MMR/ MMR- $V$ vaccination as a matter of routine in primary care, as the vaccine does not contain egg allergen.

\section{Recommendations of the Hong Kong Institute of Allergy and the Hong Kong Society for Paediatric Immunology Allergy \& Infectious Diseases}

1. All patients with suspected or confirmed egg allergy should receive the MMR/MMR-V vaccination as a matter of routine in primary care. 
TABLE. Summary of international recommendations on administrating vaccines to egg-allergic individuals

\begin{tabular}{|c|c|}
\hline Authority (country) & $\begin{array}{l}\text { Recommendations on administrating influenza vaccines to } \\
\text { egg-allergic individuals }\end{array}$ \\
\hline $\begin{array}{l}\text { Australian Society of } \\
\text { Clinical Immunology } \\
\text { and Allergy } \\
\text { (Australia) }^{6}\end{array}$ & $\begin{array}{l}\text { - Presence of egg allergy does not increase the risk of allergic } \\
\text { reactions to the influenza vaccines. } \\
\text { - Entire vaccine can be administered in community vaccination } \\
\text { clinics as a single dose followed by a 15-to-20-minute waiting } \\
\text { period. A longer waiting period ( } 30 \text { minutes) may be warranted if } \\
\text { there is significant parental or health professional anxiety. } \\
\text { - The immediate availability of a medical practitioner care is } \\
\text { recommended and staff should be familiar with the recognition } \\
\text { and treatment of anaphylaxis. } \\
\text { - Should there be anaphylaxis to influenza vaccine itself, further } \\
\text { vaccination should be avoided without specialist allergy } \\
\text { assessment. } \\
\text { - The following are not recommended: } \\
\text { o split dosing; } \\
\text { o allergy testing with the vaccine or egg prior to administration; } \\
\text { o ingestion of egg as a pre-condition to administering the } \\
\text { vaccine; } \\
\text { o vaccination in specific hospital-based vaccination clinics; } \\
\text { o allergy specialist review before influenza vaccination unless } \\
\text { anaphylaxis to the influenza vaccine itself has occurred } \\
\text { previously. }\end{array}$ \\
\hline Centers for Disease & - Any licensed and recommended flu vaccines are recommended \\
\hline
\end{tabular}

Centers for Disease Control and Prevention (US) $)^{7,14}$ - Any licensed and recommended flu vaccines are recommended
to egg-allergic individuals who have experienced urticaria only.

- Egg-allergic individuals who had other symptoms such as angioedema, respiratory distress, light-headedness or recurrent emesis, or who required epinephrine or another emergency medical intervention may receive any licensed and recommended flu vaccine. Flu vaccines should be administered in an in-patient or out-patient medical setting.

- Vaccine administration should be supervised by a health care provider who is able to recognise and manage severe allergic conditions.

- A previous severe allergic reaction to flu vaccine, regardless of the component suspected of being responsible for the reaction, is a contra-indication to future receipt of the vaccine.
Recommendations on administrating MMR/ MMR-V vaccines to egg-allergic individuals

- MMR vaccine is cultured on chicken fibroblast cell cultures, which contains no residual egg allergen and has been safely administered to large numbers of egg-allergic individuals.

- Rare allergic reactions have been attributed to nonegg ingredients such as gelatine.

- MMR-V vaccine is considered not to contain foodderived protein allergens and can be given to any patient with food allergy, even those with foodinduced anaphylaxis.

\section{American Academy of Allergy Asthma and Immunology (US) ${ }^{8}$}

- Influenza vaccines should be administered to individuals with egg allergy of any severity, just as they would be to individuals without egg allergy.

- No special precautions beyond those recommended for the administration of any vaccine to any patient are necessary for administration of influenza vaccine to egg-allergic individuals.

- Use of non-egg-based influenza vaccines, such as ccllV3 or RIV3, in egg-allergic individuals in the age-groups for which they are approved is acceptable but not medically necessary or preferred.

- Live attenuated influenza vaccine may be administered to eggallergic patients of any severity in the age-group for which it is approved (age 2-49 years), in particular countries and seasons when live attenuated influenza vaccine is recommended as an agent (based on effectiveness in prior seasons).

American Academy of - Inactivated influenza vaccine administered in a single, agePediatrics (US) $)^{9,15}$ appropriate dose is well tolerated by recipients with an egg allergy of any severity. Special precautions for egg-allergic recipients of inactivated influenza vaccine are not warranted, because the rate of anaphylaxis after inactivated influenza vaccine administration is no greater in egg-allergic than in non-egg allergic recipients from other universally recommended vaccines.

- All children with an egg allergy of any severity can receive an influenza vaccine without any additional precautions beyond those recommended for any vaccine.

- Patients who refuse to receive an egg-based vaccine may be vaccinated with an age-appropriate recombinant or cell-culture product.

- Quadrivalent live attenuated influenza vaccine is not recommended for use in any setting in the United States during the 2017-2018 influenza seasons.
- The vaccine ingredients extremely rarely cause anaphylactic reactions. Children should not get MMR-V vaccine if they have ever had a lifethreatening allergic reaction to any component of the vaccine, including gelatine or the antibiotic neomycin.

- No specific recommendations mentioned for eggallergic individuals.
- Measles vaccine is produced in chicken embryo cell culture and does not contain significant amounts of egg white (ovalbumin) cross-reacting proteins.

- Children with egg allergy are a low risk of anaphylactic reactions to measles-containing vaccines (including MMR and MMR-V).

- Skin testing of children for egg allergy is not predictive of reaction to MMR vaccine and is not recommended before administering MMR or other measles-containing vaccines.

\footnotetext{
Abbreviations: MMR = measles-mumps-rubella; MMR-V = measles-mumps-rubella-varicella; UK = United Kingdom; US = United States
} 
TABLE. (cont'd)

\begin{tabular}{|c|c|c|}
\hline Authority (country) & $\begin{array}{l}\text { Recommendations on administrating influenza vaccines to } \\
\text { egg-allergic individuals }\end{array}$ & $\begin{array}{l}\text { Recommendations on administrating MMR/ } \\
\text { MMR-V vaccines to egg-allergic individuals }\end{array}$ \\
\hline $\begin{array}{l}\text { British Society for } \\
\text { Allergy \& Clinical } \\
\text { Immunology (UK) }{ }^{10,16}\end{array}$ & $\begin{array}{l}\text { - Children with egg allergy can safely be vaccinated with Fluenz } \\
\text { Tetra (AstraZeneca UK Ltd) in any setting. } \\
\text { - Children who have previously required admission to an intensive } \\
\text { care unit for severe anaphylaxis to egg should be referred to a } \\
\text { specialist for immunisation in hospital. } \\
\text { - Fluenz Tetra should not be administered to a child with current } \\
\text { or recent acute wheezing in the } 72 \text { hours preceding vaccination, } \\
\text { or who have required oral steroids in the previous } 2 \text { weeks. } \\
\text { - Facilities and staff trained to recognise and treat anaphylaxis } \\
\text { should be available. }\end{array}$ & $\begin{array}{l}\text { - Administration of the MMR vaccine to egg-allergic } \\
\text { children has an excellent safety record and may be } \\
\text { administered to all egg-allergic children as a routine } \\
\text { procedure in primary care. } \\
\text { - The MMR vaccine is grown on cultured-embryo- } \\
\text { chick fibroblasts and is therefore generally free of } \\
\text { hen's egg protein. } \\
\text { - When traces of hen's egg protein are found, the } \\
\text { protein is highly processed and the concentrations } \\
\text { are too low to represent a risk. }\end{array}$ \\
\hline $\begin{array}{l}\text { World Allergy } \\
\text { Organization }^{11}\end{array}$ & $\begin{array}{l}\text { - Egg allergy does not appear to impart an increased risk of an } \\
\text { anaphylactic reaction to immunisation with either inactivated or } \\
\text { live attenuated influenza vaccines. } \\
\text { - Immediate hypersensitivity reactions such as urticaria are no } \\
\text { more common in egg-allergic than non-egg allergic vaccine } \\
\text { recipients. } \\
\text { - Any age-approved influenza vaccine can be used in any patient } \\
\text { irrespective of egg allergy status and that special precautions } \\
\text { are not required. }\end{array}$ & $\begin{array}{l}\text { - The manufacture of vaccines containing live virus } \\
\text { produced in chick embryo cultures (measles and } \\
\text { mumps) and human diploid cell culture (rubella) has } \\
\text { resulted in a vaccine that contains no, or at most } \\
\text { picogram quantities of egg protein, insufficient to } \\
\text { cause an allergic reaction. } \\
\text { - All children with egg allergy should receive the MMR } \\
\text { vaccination as a routine procedure in primary care. } \\
\text { - Anaphylactic reactions to MMR vaccine are not } \\
\text { associated with hypersensitivity to egg antigens but } \\
\text { to other components of the vaccine. }\end{array}$ \\
\hline $\begin{array}{l}\text { UK Department of } \\
\text { Health-The Green } \\
\text { Book }^{12}\end{array}$ & $\begin{array}{l}\text { Adults } \\
\text { - The ovalbumin-free influenza vaccine, if available, can be used } \\
\text { in any setting in patients from the age of } 18 \text { years, regardless of } \\
\text { the severity of egg allergy. } \\
\text { - Adult patients can also be immunised in any setting using an } \\
\text { inactivated influenza vaccine with an ovalbumin content }<0.12 \\
\mu \mathrm{g} / \mathrm{mL} \text { (equivalent to } 0.06 \mu \mathrm{g} \text { for } 0.5 \mathrm{~mL} \text { dose), excepting } \\
\text { those with severe anaphylaxis to egg that has previously } \\
\text { required intensive care who should be referred to specialists for } \\
\text { immunisation in hospital. } \\
\text { Children } \\
\text { - Except for those with severe anaphylaxis to egg that has } \\
\text { previously required intensive care, children with an egg allergy } \\
\text { can be safely vaccinated with Fluenz Tetra in any setting } \\
\text { (including primary care and schools). } \\
\text { - Those with clinical risk factors that contra-indicate Fluenz Tetra } \\
\text { should be offered an inactivated influenza vaccine with a very } \\
\text { low ovalbumin content ( }<0.12 \mu \mathrm{m} / \mathrm{mL} \text { ). }\end{array}$ & \\
\hline
\end{tabular}

2. Influenza vaccines can be safely administered, and are recommended, for disease prevention in eggallergic individuals. They are recommended to be administered in an out-patient or ambulatory setting.

3. Only those patients who have previously required admission to an intensive care unit for severe anaphylaxis to egg should be referred to an allergist for further evaluation prior to influenza vaccination.

4. Should there be any significant concerns from patients, parents or health care professionals, health care professionals who are capable of recognising signs and symptoms of an allergic reaction can provide 15 to 30 minutes of monitoring following vaccination.

5. Specialist evaluation is recommended prior to yellow fever vaccination in egg-allergic individuals (Fig).

6. Individuals who have developed or are suspected to have developed an allergic reaction to the vaccine or other vaccine components (such as gelatine or neomycin) should not undergo further vaccination with these products. Referral to an allergy specialist for further evaluation can be considered (Fig).

7. A significant number of suspected egg-allergic patients may be misdiagnosed, so referral to an allergist for evaluation may be considered.

\section{Author contributions}

GT Chua and PH Li drafted the main text of the article, including the tables and figures. E Lai and V Ngai offered their expert opinion as clinical pharmacists and contacted pharmaceutical companies regarding the contents of the vaccines. MHK Ho, MYW Kwan, FYS Yau, TF Leung, and TH Lee contributed to the concept, analysis, and critical revision of the article.

\section{Funding/support}

This research received no specific grant from any funding agency in the public, commercial, or not-for-profit sectors. 


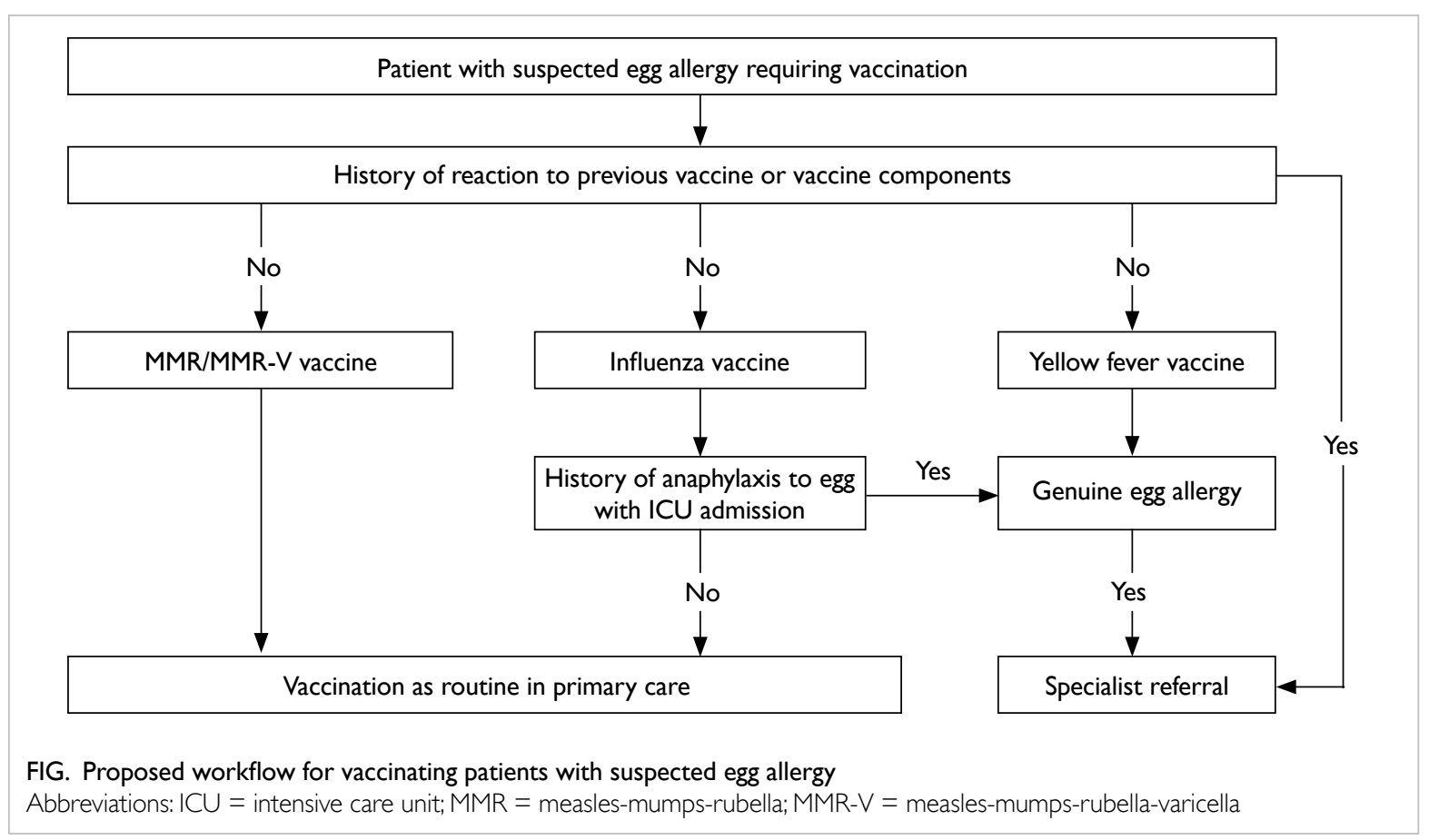

\section{Declaration}

All authors have disclosed no conflicts of interest. All authors had full access to the data, contributed to the study, approved the final version for publication, and take responsibility for its accuracy and integrity.

\section{References}

1. Leung TF, Yung E, Wong YS, Lam CW, Wong GW. Parentreported adverse food reactions in Hong Kong Chinese pre-schoolers: epidemiology, clinical spectrum and risk factors. Pediatr Allergy Immunol 2009;20:339-46.

2. Ho MH, Lee SL, Wong WH, Ip P, Lau YL. Prevalence of self-reported food allergy in Hong Kong children and teens-a population survey. Asian Pac J Allergy Immunol 2012;30:275-84.

3. Li PH, Wagner A, Rutkowski R, Rutkowski K. Vaccine allergy: a decade of experience from 2 large UK allergy centers. Ann Allergy Asthma Immunol 2017;118:729-31.

4. Centre for Health Protection, Department of Health, Hong Kong SAR Government. Frequently asked question on seasonal influenza vaccine 2015/16. Q14. Who should not receive inactivated seasonal influenza vaccination? Available from: http://www.chp.gov.hk/en/view_content/ 26837.html. Accessed 20 Nov 2017.

5. Moneret-Vautrin DA, Kanny G. Update on threshold doses of food allergens: implications for patients and the food industry. Curr Opin Allergy Clin Immunol 2004;4:215-9.

6. ASCIA Guidelines-Vaccination of the Egg-allergic Individual. Australian Society of Clinical Immunology and Allergy; 2017.

7. Centers for Disease Control and Prevention, Department of Health \& Human Service, USA Government. Flu vaccine and people with egg allergies. Available from: https://www. cdc.gov/flu/protect/vaccine/egg-allergies.htm. Accessed 20 Nov 2017.

8. Greenhawt M, Turner PJ, Kelso JM. Administration of influenza vaccines to egg-allergic recipients: a practice parameter update 2017. Ann Allergy Asthma Immunol 2018;120:49-52.

9. Committee on Infectious Diseases. Recommendations for prevention and control of influenza in children, 2017-2018. Pediatrics 2017;140:e20172550.

10. British Society for Allergy \& Clinical Immunology Paediatric Committee. 2015/16 Influenza vaccine recommendations for children with egg allergy. Available from: http://www.bsaci.org/Guidelines/Flu\%20jab\%20 egg\%20allergic\%20kids.pdf. Accessed 20 Nov 2017.

11. Dreskin SC, Halsey NA, Kelso JM, et al. International Consensus (ICON): allergic reactions to vaccines. World Allergy Organ J 2016;9:32.

12. United Kingdom government. The Green Book. 2014. Available from: https://www.gov.uk/government/ collections/immunisation-against-infectious-disease-thegreen-book. Accessed 20 Nov 2017.

13. Family Health Service. Department of Health. Hong Kong SAR Government. Hong Kong childhood immunization programme. Available from: http://www.fhs.gov.hk/ english/main_ser/child_health/child_health_recommend. html. Accessed 20 Nov 2017.

14. Centers for Disease Control and Prevention. Vaccine safety-measles, mumps, rubella, and varicella vaccine. Available from: https://www.cdc.gov/vaccinesafety/ vaccines/mmrv-vaccine.html. Accessed 20 Nov 2017.

15. American Academy of Pediatrics. Measles. In: Kimberlin DW, Brady MY, Hackson MA, editors. Red Books: 2015 Report of the Committee on Infectious Diseases. 30th ed. Elk Grove Village, IL: American Academy of Pediatrics; 2015.

16. British Society for Allergy \& Clinical Immunology. BSACI recommendations for combined measles, mumps and rubella (MMR) vaccination in egg-allergic children. 2007. Available from: http://www.bsaci.org/guidelines/ mmreggrecommendations.pdf. Accessed 20 Nov 2017. 